\title{
Knowledge and attitude of adults on kidney donation in selected village of Udupi district, Karnataka.
}

\author{
Mrs. Leena Sequira ${ }^{1}$, Dr. Mamatha $S$ Pai $^{2}$ \\ ${ }^{I}$ (Medical Surgical Nursing, Manipal College of Nursing / Manipal University, India) \\ ${ }^{2}$ (Child Health Nursing, Manipal College of Nursing / Manipal University, India)
}

\begin{abstract}
To assess the knowledge and attitude of adults on kidney donation, a descriptive survey was carried out in one of the villages of Udupi District. Objectives of the study were to assess the knowledge and attitude of adults on kidney donation, to find the correlation between knowledge and attitude and to find the association between knowledge and gender, marital status and education.

A survey approach was used for the study. Hundred adults aged 19 years and above were included in the study. Tools used for data collection were demographic proforma, knowledge and attitude questionnaire on kidney donation. Convenience sampling method was used for selecting the sample.

Among 100 participants recruited for the study, 64\% were between the age group of 19-40 years, 60\%of them were females. Most of the adults were graduates (52\%) and majority (89\%) of them were Christians. . With regard to the knowledge on kidney donation, it was observed that $76 \%$ had good knowledge and $88 \%$ of adults had unfavourable attitude towards kidney donation. A significant association was found between the knowledge and gender, education and religion. ( $p$ value $=0.009,0.001$ and 0.003 respectively). There was a weak correlation between the knowledge and attitude of adults on kidney donation $(r=0.20 p=0.041)$.
\end{abstract}

Keywords: adults, attitude, Kidney donation, knowledge.

\section{INTRODUCTION}

The need of kidney transplant is increasing year by year. According to the Indian transplant Registry, number of kidney transplant in 2000 was 1137 which increased to 1214 in 2004. [1]. Kidney transplants in India first started in 1970s and since that time, India has been a leading country in this field on the Asian subcontinent. In India, despite the Transplant of Human Organs Act (THO), neither has the commerce stopped nor have the number of deceased donors increased to take care of organ shortage [2]. The studies carried out in India stresses the importance of increased public awareness on the need for deceased donor organs [3, 4,5]. Problems and mortality among people with kidney disease are increasing that necessitates the importance of finding the knowledge and attitude of adults about kidney donation.

This study was carried out to get an understanding of the knowledge and attitude of adults towards organ donation and to find the factors associated with the same among the adults living in selected villages in Udupi Distrcit, India.

\section{METHODOLOGY}

The study used survey approach with descriptive survey design. The population for the study was adults aged between 19-60 years residing in one of the villages covered under Udupi District of South Karnataka, India. Adults aged between 19-60 years and holding membership in any one of the social organization such as Jaycees, Lions or Rotary club was the inclusion criteria to select the sample for the study. This study consisted of 100 adults chosen using convenient sampling method.

\subsection{Data collection instruments}

The instruments used for data collection were:

Demographic proforma

To understand the characteristics of the participants, the items included in the Demographic proforma were age, gender, marital status, education, occupation and religion.

Knowledge questionnaire

Knowledge questionnaire consisted of 24 items related to various aspects of kidney donation. Maximum possible score was 24 . Score between 18 to 24 is considered as good knowledge and score below 18 is considered as poor knowledge. 
Attitude questionnaire

Attitude scale was a five point likert type scale consisted of 12 items ( 05 as strongly agree and 01 as strongly disagree). Maximum possible score was 60 . Score above 40 is considered as favorable attitude and score below 40 were considered as unfavorable attitude.

Content validity of the instruments were established by taking the suggestions from the experts from nephrology and nursing. The tools were modified based on the suggestions given by the experts.

The reliability of the knowledge questionnaire was established by using spilt half technique and Spearman Brown prophecy formula ( $\mathrm{r}=0.78)$, attitude questionnaire was done using Crohnbach's Alfa $(\mathrm{r}=0.8)$.

\subsection{Data collection procedure}

Data were collected in one of the villages in Udupi District by meeting the adults from January 2013 to November 2013. Adults were explained about the study and informed written consent was obtained. Participants of the study were instructed to read and fill the questionnaire on knowledge and attitude.

\subsection{Ethical considerations}

The study was approved by Institutional Review Committee (IRC) and Institutional Ethics Committee of Kasturba Hospital, Manipal. (IEC 544/2012). Written informed consent was taken from the participants and they were assured of confidentiality.

\section{RESULTS}

\subsection{Sample characteristics}

Out of 100 participants, $54 \%$ of the sample was between the age group of $19-40$ years, $60 \%$ of them were females. Most of the adults were graduates (52\%) and majority (89\%) of them were Christians. (Table 1)

Table 1: Sample Characteristics
\begin{tabular}{|l|l|l|}
\hline \multirow{2}{*}{ Age in years } & Variables & Frequency(f) \& \% \\
\cline { 2 - 4 } & $19-40$ & 64 \\
\cline { 2 - 4 } \multirow{2}{*}{ Marital status } & $41-60$ & 36 \\
\hline \multirow{2}{*}{ Gender } & Unmarried & 47 \\
\cline { 2 - 3 } & Married & 53 \\
\hline \multirow{2}{*}{ Education } & Female & 60 \\
& Male & 40 \\
\hline \multirow{4}{*}{ Occupation } & Graduation and above & 52 \\
\cline { 2 - 3 } & Below graduation & 48 \\
\hline \multirow{3}{*}{ Religion } & Skilled & 28 \\
\cline { 2 - 3 } & Unskilled & 11 \\
\cline { 2 - 3 } & Other & 61 \\
\hline & Christian & 89 \\
\cline { 2 - 3 } & Hindu & 01 \\
\cline { 2 - 3 } & Muslim &
\end{tabular}

$\mathbf{n}=\mathbf{1 0 0}$

\subsection{Knowledge and attitude of adults on Kidney donation:}

With regard to the knowledge on kidney donation, it was observed that $76 \%$ had good knowledge and $88 \%$ of adults had unfavorable attitude towards kidney donation. Mean knowledge score was 14.9 and the attitude was 31.92. (Table 2)

Table 2. Distribution of sample based on knowledge andattitude score $\quad \mathbf{n = 1 0 0}$

\begin{tabular}{|l|l|c|l|}
\hline \multicolumn{1}{|c|}{ Variables } & Knowledge & Frequency \& \% & Mean and SD \\
\hline \multirow{2}{*}{ Knowledge on kidney donation } & Good & 74 & $14.9 \pm 3.90$ \\
\cline { 2 - 3 } & Poor & 26 & \\
\hline \multirow{2}{*}{ Attitude regarding kidney donation } & Favorable & 12 & \multirow{2}{*}{$31.92 \pm 6.99$} \\
\cline { 2 - 3 } & Unfavorable & 88 & \\
\hline
\end{tabular}

Attitude of adults in selected items:

The item wise frequency on attitude showed that only $35 \%$ of adults like to donate kidney but $45 \%$ of adults said that they would recommend a relative to donate kidney. $55 \%$ of the adults said that "it is good thing to donate kidney but not me." 


\subsection{Correlation between knowledge and attitude:}

To find the relationship between knowledge and attitude, correlation was computed and the Correlation coefficient obtained was $r=0.205(p=0.041)$. The result showed a weak correlation between knowledge and attitude scores of adults on kidney donation.

\subsection{Association between Knowledge and selected variable:}

To find the association between the knowledge and selected variables chi square was computed (Table 3). Statistically significant association was present between knowledge level of the adults and gender, education and religion. However, there was no significant association between knowledge and marital status and age of the adults. Younger the age knowledge was better and females had higher knowledge score than males.

Table 3: Chi-Square values computed between the knowledge scores and selected variables $\mathbf{n}=100$

\begin{tabular}{|l|l|c|c|l|l|}
\hline \multicolumn{1}{|c|}{ Variable } & \multicolumn{1}{|c|}{ Category } & Good & Poor & Chi-Square & P value \\
\hline Age & $19-40$ & 47 & 17 & 0.029 & 0.864 \\
& $41-60$ & 27 & 09 & & \\
\hline Gender & Male & 24 & 16 & 6.791 & 0.009 \\
& Female & 50 & 10 & & \\
\hline Education & Graduation and above & 21 & 31 & 11.651 & 0.001 \\
& Below graduation & 05 & 43 & & \\
\hline Marital & Married & 16 & 37 & 1.028 & 0.311 \\
status & Unmarried & 10 & 37 & & \\
& & & & & \\
\hline Religion & Christians & 19 & 70 & 9.099 & \\
& Hindu \&Muslim & 07 & 04 & & \\
\hline
\end{tabular}

IV.

\section{DISCUSSION}

The aim of this study was to find the knowledge and attitude of adults regarding kidney donation. It was found that majority of the adults had good knowledge regarding kidney donation. Findings of this study are comparable with the studies carried out by Khan $\mathrm{N}$ et.al. which reported statistical significance between knowledge and gender.. This study also reported that knowledge and age were not significantly associated (5). The study carried out by Mithra P et.al showed that $59.6 \%$ of the participants expressed willingness to donate organs (4).

Generally the attitude of the adults regarding kidney donation was not favourable. The number participants who would recommend relatives to donate kidney were more than those who expressed to donate kidney themselves.

\section{CONCLUSION}

This study was able to give an idea about the knowledge and attitude regarding kidney donation in adult population. Findings of this study suggest the need for an awareness program for adults regarding kidney donation to discuss various areas of kidney donation. Sample size of this study was only 100 and conveniently selected. Lack of participants from all religion poses limitations for the generalizability of the study results.

\section{REFERENCES}

[1] Indian Transplant Registry of Indian Society of Organ Transplantation. http://www.transplantindia.com/new/Reports/FasttrackTotalTransplantionReport.aspx (Retrieved on $29^{\text {th }}$ January 2014).

[2] Shroff S. Legal and ethical aspects of organ donation and transplantation. Indian J Urol, 25, 2009, 348-55. [PMC free article] [PubMed).

[3] M. R. Gumber, V. B. Kute, K. R. Goplani, P. R. Shah, H. V. Patel, A. V. Vanikar, P. R. Modi, H. L. Trivedi. Deceased donor organ transplantation: A single center experience. Indian J Nephrol, 21(3), 2011 Jul-Sep, 182-185.

[4] Mithra P, Prithvishree R, B Unnikrishnan, T Rekha, Tanuj K, Nithin Kumar, Mohan P, Vaman K, Ramesh H, and K Divyavaraprasad. Perceptions and Attitudes Towards Organ Donation Among People Seeking Healthcare in Tertiary Care Centers of Coastal South IndiaIndian J Palliat Care, 19(2), 2013 May-Aug, 83-87.

[5] Khan N, Masood Z, Nadia Tufail, Hina Shoukat, KTA Ashraf, Sumera Ehsan, Sabeeka Zehra, Nosheen Battol, Sadia Akram, Sehrish Khalid. Knowledge and attitude of people towards organ donation. JUMD, 2( 2), Jul-Dec 2011, 15-21. 